\title{
Genetic consequences of terminal crossbreeding, genomic test, sexed semen, and beef semen in dairy herds
}

\author{
J. B. Clasen, ${ }^{1 *} \odot$ M. Kargo, ${ }^{2,3} \odot$ S. Østergaard, ${ }^{4}{ }^{\oplus}$ W. F. Fikse, ${ }^{5} \odot$ L. Rydhmer, ${ }^{1} \odot$ and E. Strandberg ${ }^{1} \odot$ \\ ${ }^{1}$ Department of Animal Breeding and Genetics, Swedish University of Agricultural Sciences, Box 7023, 75007 Uppsala, Sweden \\ ${ }^{2}$ Center for Quantitative Genetics and Genomics, Aarhus University, Blichers Allé 20, DK-8830 Tjele, Denmark \\ ${ }^{3}$ SEGES, Danish Agriculture and Food Council, Agro Food Park 15, DK-8200 Aarhus N, Denmark \\ ${ }^{4}$ Department of Animal Science, Aarhus University, Blichers Allé 20, DK-8830 Tjele, Denmark \\ ${ }^{5}$ Växa Sverige, Swedish University of Agricultural Sciences, Ulls väg 26, 75651 Uppsala, Sweden
}

\begin{abstract}
The development of breeding tools, such as genomic selection and sexed semen, has progressed rapidly in dairy cattle breeding during the past decades. In combination with beef semen, these tools are adopted increasingly at herd level. Dairy crossbreeding is emerging, but the economic and genetic consequences of combining it with the other breeding tools are relatively unknown. We investigated 5 different sexed semen schemes where 0,50 , and $90 \%$ of the heifers; $50 \%$ of the heifers $+25 \%$ of the first-parity cows; and $90 \%$ of the heifers $+45 \%$ of the first-parity cows were bred to sexed semen. The 5 schemes were combined in scenarios managing purebreeding or terminal crossbreeding, including genomic testing of all newborn heifers or no testing, and keeping Swedish Red or Swedish Holstein as an initial breed. Thus, 40 scenarios were simulated, combining 2 stochastic simulation models: SimHerd Crossbred (operational returns) and ADAM (genetic returns). The sum of operational and genetic returns equaled the total economic return. Beef semen was used in all scenarios to limit the surplus of replacement heifers. Terminal crossbreeding implied having a nucleus of purebred females, where some were inseminated with semen of the opposite breed. The $\mathrm{F}_{1}$ crossbred females were inseminated with beef semen. The reproductive performance played a role in improving the benefit of any of the tools. The most considerable total economic returns were achieved when all 4 breeding tools were combined. For Swedish Holstein, the highest total economic return compared with a pure-breeding scenario, without sexed semen and genomic test, was achieved when $90 \%$ sexed semen was used in heifers and $45 \%$ sexed semen was used for first-parity cows combined with genomic
\end{abstract}

Received December 11, 2020.

Accepted February 18, 2021.

*Corresponding author: julie.clasen@slu.se test and crossbreeding $(+€ 58,33 \%$ crossbreds in the herd). The highest total economic return for Swedish Red compared with a pure-breeding scenario, without sexed semen and genomic test, was achieved when $90 \%$ sexed semen was used in heifers combined with genomic test and crossbreeding (+€94, 46\% crossbreds in the herd). Terminal crossbreeding resulted in lower genetic returns across the herd compared with the corresponding pure-breeding scenarios but was compensated by a higher operational return.

Key words: sexed semen, genomic selection, beef semen, dairy crossbreeding, herd economy

\section{INTRODUCTION}

Dairy cattle breeding has progressed rapidly during the past decades due to new breeding tools, such as genomic selection and sexed semen (SS). In less than a decade, genomic selection revolutionized dairy cattle breeding and made it possible to select young bulls with reliabilities of breeding values nearly as high as reliabilities for daughter-proven AI bulls for all kinds of traits. For farmers, genomic testing (GT) is an opportunity to more accurately select replacement heifers before they are bred and reduce the genetic lag between the herd and the breeding population (Buch et al., 2012; García-Ruiz et al., 2016). The use of SS enhances the chance of getting female offspring to about 90\% (e.g., Borchersen and Peacock, 2009), making it possible for farmers to ensure a sufficient number of future replacement heifers. Also, by ensuring future replacement heifers are born from the best cow dams, genetic lag can be reduced (Weigel, 2004; Sørensen et al., 2011; Ettema et al., 2017). A dose of SS is usually more expensive than conventional semen (CS), and the conception rate with SS is 70 to $95 \%$ of the conception rate with CS (Borchersen and Peacock, 2009; Butler et al., 2014; Maicas et al., 2020). Combining SS with GT has shown positive interaction effects on genetic gain and thereby economic return at herd level (Calus et al., 2015; Hjortø 
et al., 2015; Bérodier et al., 2019). However, economic and genetic benefits at herd level of using SS and GT differs between farms and management systems and are mainly dependent on reproduction level, rearing costs, and market prices for replacement heifers $(\mathrm{McCullock}$ et al., 2013; Hjortø et al., 2015; Newton et al., 2018). Furthermore, by combining SS with beef semen (BS), it potentially increases genetic and economic benefits at herd level (Hjortø et al., 2015; Ettema et al., 2017), and additionally, it benefits favorably on the climate footprint by increasing the beef efficiency from dairy farms (Holden and Butler, 2018).

The proportion of dairy herds that use SS and GT differs between countries but generally increases. In Denmark, the proportion of farmers using more than $10 \%$ SS on Holstein heifers has increased from $28 \%$ in 2011 (SEGES, 2011) to $60 \%$ in 2020 (SEGES, 2020). In the United Kingdom, the sales of SS doses have more than doubled between 2012 and 2019. In Sweden, the proportion of SS inseminations is still very low (5\%; Växa Sverige, 2019). The number of GT heifers in Denmark, Sweden, and Finland (DFS) has increased 5 times between 2012 and 2017 (Nielsen et al., 2019). However, only about $12 \%$ of heifers born each year in DFS are genomically tested (Bengtsson et al., 2020).

Crossbreeding between dairy cattle breeds has been known for at least a century as an effective breeding strategy to use complementary traits and heterosis (Touchberry, 1992; Sørensen et al., 2008). However, the frequency of crossbreeding is relatively low in European countries (Dezetter et al., 2017; Clasen et al., 2019a), the United States, and Canada (Norman et al., 2018), whereas crossbreeding has become the primary breeding strategy in New Zealand (DairyNZ, 2021). Studies on the economic benefits of systematic crossbreeding at herd level have been sparse, but more recent studies showed positive economic benefits of crossbreeding (Dezetter et al., 2017; Shonka-Martin et al., 2019; Clasen et al., 2020a).

Several studies have already pointed out genetic and economic consequences of combining GT, SS, and BS, but studies on the effects of combining one or more of these tools with crossbreeding are limited - especially regarding the genetic lag and rate of genetic progress. This simulation study aimed to investigate the operational and genetic return using GT, SS, BS, and crossbreeding at herd level in herds based on Swedish Holstein (SH) or Swedish Red (SR). Due to the lack of genomic breeding values for crossbred animals, they are not relevant for GT, and therefore we simulated a terminal crossbreeding strategy, where all crossbred and purebred replacement heifers were born from purebred dams. Our long-term goal is to improve the economy of milk production by providing new knowledge on the combined effects of GT, SS, BS, and dairy crossbreeding as a base for decisions at herd level.

\section{MATERIALS AND METHODS}

\section{Herd Scenarios}

Two base herd scenarios were set up with 100 cows of either purebred $\mathrm{SH}$ or SR that resembled average Swedish herds in a conventional production system. The base herds were combined with different scenarios of pure-breeding (PB) or terminal crossbreeding (XB) with SH or SR and with or without GT. Sexed semen was used on heifers and first-parity cows in some scenarios. An overview of how the breeding tools were combined in 40 different scenarios is presented in Table 1.

The scenarios were simulated using a combination of 2 stochastic models: SimHerd Crossbred (Østergaard et al., 2018) and ADAM (Pedersen et al., 2009). SimHerd Crossbred is a modified version of SimHerd (Østergaard et al., 2005) and was used to simulate the effects of crossbreeding, SS, and BS on herd dynamics. The output from SimHerd Crossbred describing the flow of animals born and culled in the herd was used to specify input parameters in ADAM to simulate breeding values of the animals and genetic progress of the breeding scheme. The combination of SimHerd and ADAM has been used successfully in other studies (Hjort $\varnothing$ et al., 2015; Ettema et al., 2017; Clasen et al., 2019b).

Table 1. Herd scenarios having purebred Swedish Red (SR) or Swedish Holstein (SH) combined with sexed semen (SS) used in heifers and first-parity cows, crossbreeding or no crossbreeding, and genotyping or no genotyping

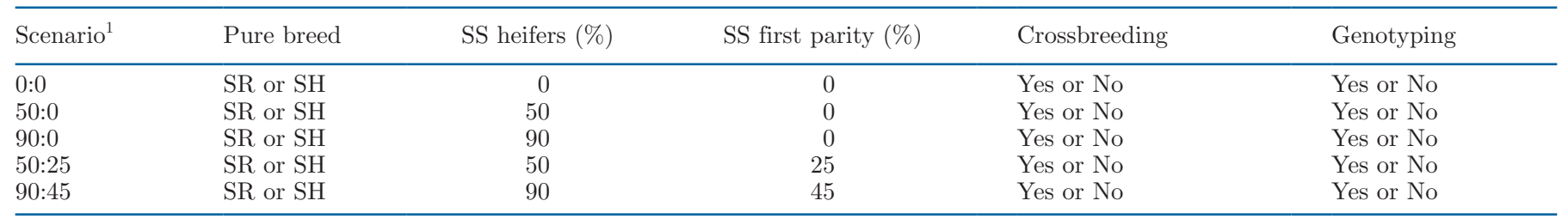

${ }^{1}$ Ratios of heifers to first-parity cows that received SS. 
Table 2. Phenotypic breed estimates ${ }^{1}$ of Swedish Holstein (SH) and Swedish Red (SR) and heterosis estimates in crosses between the breeds for production, risk of diseases, reproduction, and mortality traits used in the model simulating a conventional production system

\begin{tabular}{lrrc}
\hline Trait & SH & SR & $\begin{array}{c}\text { Heterosis } \\
(\%)\end{array}$ \\
\hline 305-d kg ECM, first parity & 8,822 & 8,369 & +3 \\
305-d kg ECM, second parity & 10,508 & 9,586 & +3 \\
305-d kg ECM, later parities & 10,957 & 9,873 & +3 \\
Mastitis (\%) & 10.2 & 7.8 & - \\
Hoof-related diseases (\%) & 21.6 & 16.8 & -10 \\
Other diseases (\%) & 2.7 & 2.1 & -10 \\
Dystocia (\%) (\%) & 5.6 & 4.6 & -7 \\
Cow mortality (\%) & 6.2 & 3.5 & -10 \\
Calf mortality (including stillbirth, \%) & 8.7 & 5.3 & -12 \\
Youngstock mortality (\%) & 3.7 & 4.1 & -12 \\
Conception rate (cows, \%) & 35 & 45 & +10 \\
Age at first service (mo) & 17.6 & 17.9 & - \\
Calving to first AI (d) & 80 & 77 & -
\end{tabular}

${ }^{1}$ Data from the Swedish milk recording scheme. The data set consisted of 687,828 milk records from SH cows and 440,924 milk records from SR cows.

${ }^{2}$ Based on Jönsson (2015). All estimates are favorable.

\section{SimHerd Crossbred Simulations}

Inputs describing breed estimates and heterosis in the crossbred animals were the same as recently used by Clasen et al. (2020a). The breed estimates originated from the Swedish cattle database (managed by Växa Sverige, Uppsala), whereas the heterosis estimates were based on a study by Jönsson (2015), shown in Table 2 . The herd management procedures in the simulations were the same as described in Clasen et al. (2020a). We used the same prices for milk, feed, carcass, live animals, and veterinarian expenses. The price for a dose of SS was €35, and the price for a dose of CS and a dose of BS was $€ 20.5$, which were approximately the average prices in May 2020 for SR, SH, and beef breed sires, not including AI service (Växa Sverige, 2020).
Terminal crossbreeding in the XB scenarios implied having a herd of partly purebred SH or SR (nucleus), and partly $\mathrm{F}_{1}$ crosses of $\mathrm{SR} \times \mathrm{SH}$ or $\mathrm{SH} \times \mathrm{SR}$. The crossbred females were inseminated with BS; thus, the purebred nucleus was essential for providing replacement heifers of both purebreds and crossbreds. The size of the nucleus (i.e., the proportion of the purebreds necessary to keep in the herd to ensure enough replacement heifers) depended on the use of SS in each scenario and the parameters for reproduction and mortality in both heifers and cows. Therefore, presimulations were necessary to decide the proportions of the purebred females that should be used for PB and crossbreeding. As part of the breeding strategy, all heifers in the nucleus were selected for PB, whereas the oldest cows were selection candidates for crossbreeding. In the SimHerd Crossbred model, breed and age distinguished the animals. Selection for PB occurred randomly within 3 groups; heifers, first-parity cows, and older cows. Thus, cows in second parity and older were pooled in the same group from where they were randomly chosen for pure-breeding and crossbreeding, which means that a second parity cow was just as likely to be used for pure-breeding as, for example, a fifth parity cow. The proportions of the purebreds used for pure-breeding and crossbreds are presented in Table 3. Figure 1 illustrates the distribution of females in the XB scenario corresponding to SH with $90 \% \mathrm{SS}$ in heifers and $45 \%$ SS in first-parity cows.

Sexed semen was limited to 2 attempts per female bred to SS to simulate standard practice in Swedish dairy herds. Thereafter, CS was used. The a priori rate of conception with CS was set to 0.625 for heifers of both breeds, 0.35 for $\mathrm{SH}$ cows, and 0.45 for SR cows regardless of parity number. The chance of conception with SS was assumed to 0.85 the conception rate for CS.

\begin{tabular}{|c|c|c|c|c|}
\hline Pure breed ${ }^{1}$ & Scenario $^{2}$ & XB first parity (\%) & XB older (\%) & Crossbreds (\%) \\
\hline \multirow[t]{5}{*}{$\mathrm{SH}$} & 0:0 & 0 & 10 & 5 \\
\hline & 50:0 & 10 & 40 & 20 \\
\hline & 90:0 & 10 & 65 & 27 \\
\hline & $50: 25$ & 10 & 50 & 23 \\
\hline & $90: 45$ & 10 & 85 & 33 \\
\hline \multirow[t]{5}{*}{ SR } & 0:0 & 10 & 60 & 34 \\
\hline & 50:0 & 10 & 80 & 40 \\
\hline & 90:0 & 10 & 100 & 46 \\
\hline & $50: 25$ & 10 & 85 & 42 \\
\hline & $90: 45$ & 15 & 100 & 46 \\
\hline
\end{tabular}

${ }^{1} \mathrm{SH}=$ Swedish Holstein; $\mathrm{SR}=$ Swedish Red.

${ }^{2}$ Ratios of heifers to first-parity cows that received SS. 


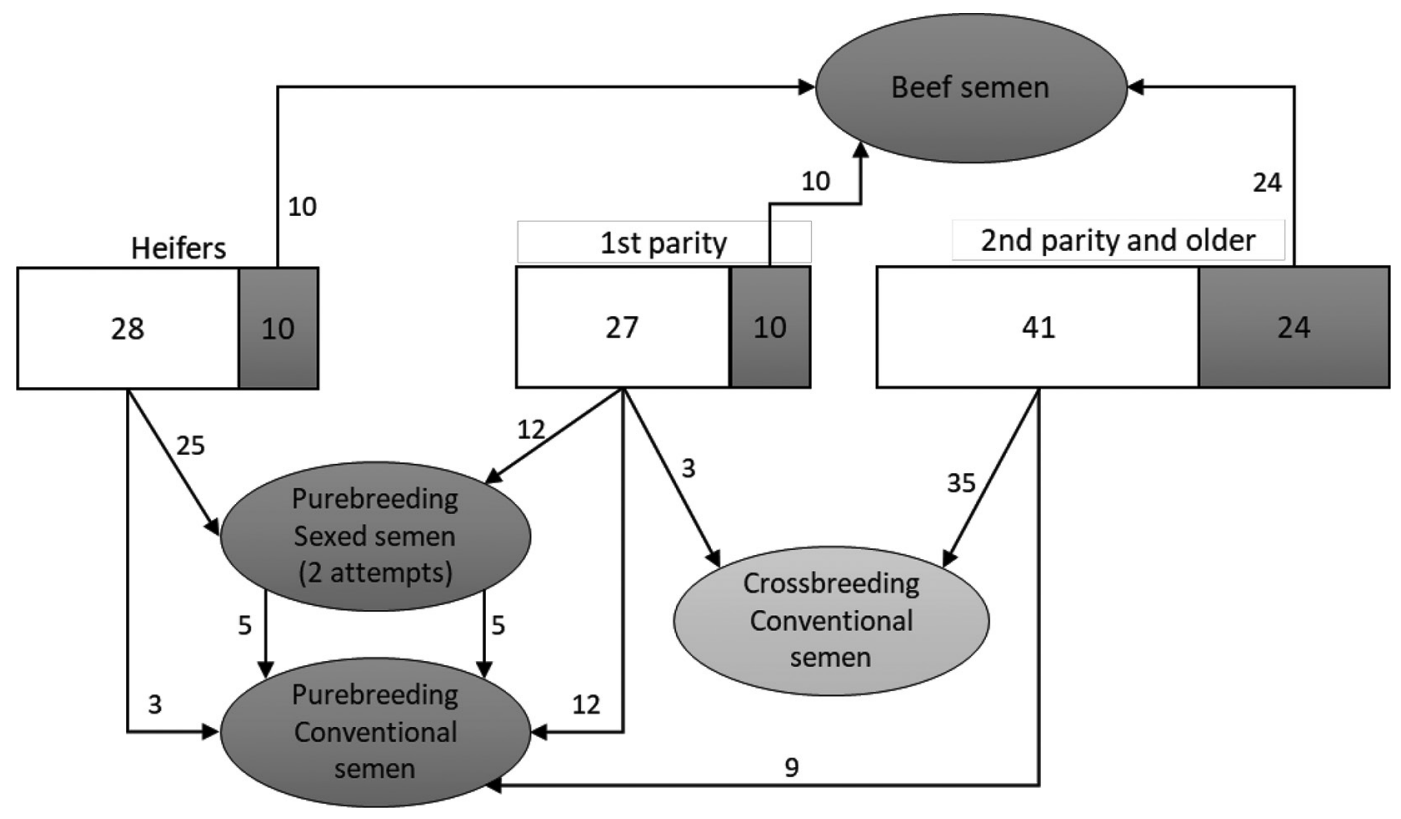

Figure 1. Illustration of the distribution of females in the breeding scheme for the scenario based on terminal crossbreeding with Swedish Holstein in the nucleus, using $90 \%$ sexed semen in heifers and $45 \%$ sexed semen in first-parity cows. The numbers within the white boxes indicate the number of purebred Swedish Holstein females within the age group. The numbers within the gray boxes indicate the number of crossbred Swedish Red $\times$ Swedish Holstein females within the age group. The numbers connected to the arrows indicate the number of females from the respective age group bred to sexed, conventional (pure-breeding or crossbreeding), and beef semen, respectively, in SimHerd Crossbred.

Beef semen was used to limit the surplus of heifers in the PB scenarios. The proportion of BS depended, as did the proportion of crossbreds in the crossbreeding scenarios, on the amount of SS, reproduction, and mortality parameters, and was therefore presimulated for the PB scenarios. In these scenarios, the older cows were selection candidates for BS, pooled in groups of third parity and older cows, with second-parity cows, first-parity cows, and heifers in separate groups. The results of the presimulations of $\mathrm{BS}$ in the $\mathrm{PB}$ scenarios are presented in Table 4. Figure 2 illustrates the distribution of females in the PB scenario corresponding to SH with $90 \%$ SS in heifers and $45 \%$ SS in first-parity cows.

In scenarios that included GT, all purebred heifers born in the herd were genotyped. Crossbred heifers were not genotyped, because they were not selected to produce replacement heifers. The price for genotyping was set to $€ 22.5$, which corresponds to the lowest price at the time of simulation on the Swedish market using tissue sampling tags to collect DNA samples with ear tagging simultaneously.

In contrast to the previous study by Clasen et al. (2020a), we included labor costs for young stock reared for replacement in the herd. The yearly labor cost per replacement heifer was set to €261.6 (Länsstyrelsen Västra Götaland, 2019). Labor costs associated with cows and capital costs were not included, as they were assumed the same across all scenarios.

\section{ADAM Simulations}

Using outputs from the SimHerd Crossbred simulations describing the replacement rate, the distribution of females available in the herd, and females born from different age groups, input parameters for the herd selection scheme were constructed for ADAM. Hence,

Table 4. Proportions of purebred second-parity cows and older cows bred to beef semen (BS) in the pure-breeding scenarios using different proportions of sexed semen (SS) in heifers and first-parity cows

\begin{tabular}{lccc}
\hline Pure breed $^{1}$ & Scenario $^{2}$ & $\begin{array}{c}\text { BS second } \\
\text { parity }(\%)\end{array}$ & $\begin{array}{c}\text { BS older } \\
(\%)\end{array}$ \\
\hline SH & $0: 0$ & 0 & 25 \\
& $50: 0$ & 0 & 60 \\
& $90: 0$ & 15 & 100 \\
& $50: 25$ & 0 & 85 \\
SR & $90: 45$ & 60 & 100 \\
& $0: 0$ & 0 & 90 \\
& $50: 0$ & 20 & 100 \\
& $90: 0$ & 70 & 100 \\
& $50: 25$ & 40 & 100 \\
\hline
\end{tabular}

${ }^{1} \mathrm{SH}=$ Swedish Holstein; SR = Swedish Red.

${ }^{2}$ Ratios of heifers to first-parity cows that received SS. 
both models simulated the same herd dynamics in each scenario.

Within the simulated herd, females were selected according to the selection scheme composed from the SimHerd Crossbred output and based on EBV or genomic EBV if the scenario included GT. Females not selected for any type of semen (SS, CS, or BS) were culled from the herd. Before selection within each age group, random culling took place to mimic the SimHerd Crossbred output replacement rates.

Besides the simulated herd, ADAM simultaneously simulated a cow population and a breeding population. The cow population represented any other herd in Sweden, and the only function of this population was to provide replacement heifers to the simulated herd, in case needed. However, because the initial simulations in SimHerd Crossbred defined a surplus of heifers, the support from the cow population was only needed in ADAM due to variation between replicates. The breeding population consisted of bull dams and AI bulls that contributed with semen to the simulated herd and the cow population. Each year, 1,000 out of 2,500 young bulls were selected for genotyping, and the 100 bulls with the highest genomic EBV were selected to have semen stored. AI bulls were available up to 4 yr of age, and the top 50 bulls were used for breeding and were mated to a maximum of 200 dams. Because SH and SR were assumed to have similar ge- netic parameters, the bulls used for pure-breeding and crossbreeding came from the same breeding population in the simulations.

Crossbreeding is not a feature in ADAM, which means that heterosis and breed effects were not included in genetic progress simulations. For that reason, SR and SH were assumed to have the same genetic parameters in the ADAM simulation and the same breeding goal. Even so, heterosis and breed differences were already accounted for in SimHerd Crossbred. Thus, the herd selection schemes differed between breed scenarios (as shown in Tables 3, 4, and 5) due to the differences in herd dynamics. The simulated breeding goal resembled the breeding goal of the Nordic Total Merit Index (NTM). Hence, the simulated population had a genetic gain corresponding to the Nordic dairy breeding schemes. This approach has been followed previously and is well described by Buch et al. (2012) and others in previous ADAM simulations. In short, only 2 traits were included in the total merit index simulated in ADAM: one that represented milk production traits and had a heritability of 0.30 , and one that represented functional traits and had a heritability of 0.04. The economic weights of the traits were $€ 83$ and $€ 82$ per genetic standard deviation. These weights were derived to reflect the correlations between milk production traits and functional traits in the NTM. For the simulation of genomic selection, 2 pseudogenomic traits were added

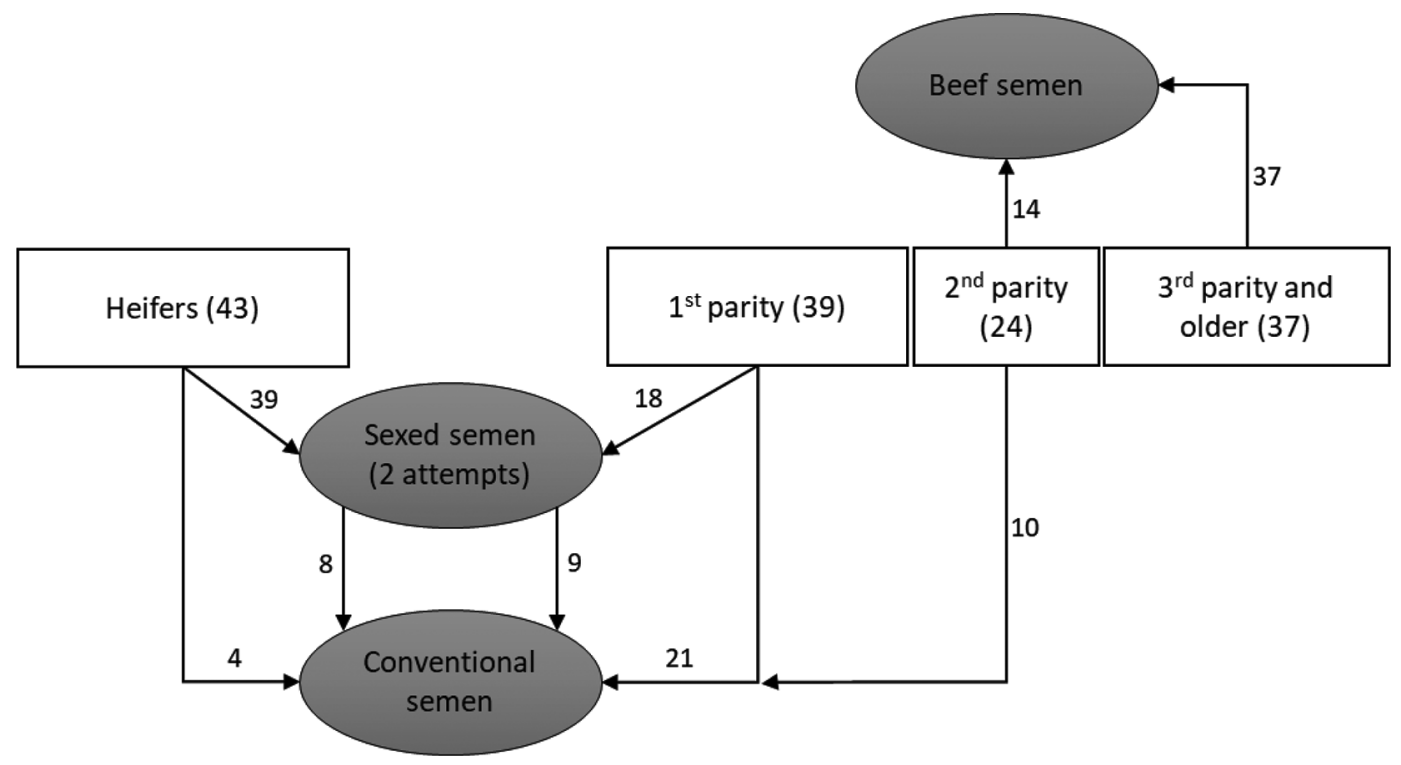

Figure 2. Illustration of the distribution of females in the breeding scheme for the scenario based on pure-breeding with Swedish Holstein using $90 \%$ sexed semen in heifers and $45 \%$ sexed semen in first-parity cows. The numbers within the white boxes indicate the number of females within the age group. The numbers connected to the arrows indicate the number of females from the respective age group bred to sexed, conventional, and beef semen, respectively, in SimHerd Crossbred. 
Table 5. Number of purebred and crossbred heifers born each year in the scenarios with pure-breeding (PB) and crossbreeding (XB) within herds having Swedish Holstein (SH) or Swedish Red (SR) in the purebred nucleus

\begin{tabular}{|c|c|c|c|c|c|c|}
\hline \multirow[b]{2}{*}{ Breed } & \multirow[b]{2}{*}{$\mathrm{PB}$ or $\mathrm{XB}$} & \multicolumn{5}{|c|}{ Sexed semen scheme (\% heifers:\% cows) } \\
\hline & & 0:0 & $50: 0$ & 90:0 & $50: 25$ & $90: 45$ \\
\hline \multirow[t]{2}{*}{$\mathrm{SH}$} & $\mathrm{PB}$ & $43: 0$ & $44: 0$ & $44: 0$ & $43: 0$ & 43:0 \\
\hline & $\mathrm{XB}$ & $42: 2$ & $35: 6$ & $32: 9$ & $32: 7$ & $28: 10$ \\
\hline \multirow[t]{2}{*}{ SR } & $\mathrm{PB}$ & $30: 0$ & 31:0 & $31: 0$ & 31:0 & 31:0 \\
\hline & $\mathrm{XB}$ & $19: 10$ & 19:12 & $18: 13$ & $18: 12$ & $17: 14$ \\
\hline
\end{tabular}

(one for the milk production trait and one for the functional trait) with heritabilities of 0.99 and with correlations to the "true" traits corresponding to a predefined accuracy of the selection index at 0.71 . This accuracy reflects the accuracy of the current NTM. See Buch et al. (2012) for a more detailed description of ADAM simulations of the NTM.

\section{Data Analysis}

The scenarios were simulated through 50 yr in SimHerd Crossbred to ensure a steady-state equilibrium. Because the SimHerd Crossbred model does not account for genetic progress, steady-state equilibrium occurred when breed proportions were steady between the years. In practice, we do not expect such a long period to implement the crossbreeding strategy fully. We simulated 50 years because the simulated transition period from pure-breeding to crossbreeding is not optimized in SimHerd Crossbred. The analyzed data were means of 1,000 replicates of the last $10 \mathrm{yr}$ of simulation. The data on herd dynamics from the various scenarios were used to calculate the operational return, expressed as $€ /$ cow-year. The operational return was calculated as sales income from milk, slaughter, and live animals minus the variable costs associated with cows and replacement heifers, labor costs associated with replacement heifers, and the cost of genotyping heifers in the relevant scenarios.

The scenarios were simulated in ADAM through 30 yr, and the analyzed data were based on means of 1,000 replicates over the last $10 \mathrm{yr}$ of simulation when the yearly genetic progress was stable. The economic value of the genetic level of heifers born each year was interpreted as the genetic return. The difference in genetic returns between scenarios illustrated the genetic lag between the scenarios, which was stable for the last 10 yr of simulation. The total return was calculated as the sum of the operational return and the genetic return, expressed as $€ /$ cow-year.

\section{Sensitivity Analysis}

A sensitivity analysis was made of the effect of labor costs associated with replacement heifers on the $\mathrm{PB}$ and XB scenarios' operational returns using the SS scheme with $90 \%$ SS in heifers and $45 \%$ SS in firstparity cows $(90: 45)$. Three levels of costs were considered: €0, €130.8, and €261.6 for both SR and SH, where $€ 261.6$ corresponded to what we simulated in the main scenarios.

Another sensitivity analysis was carried out on the effect of extreme use of SS on the total return in the XB scenarios within both dairy breeds used for insemination. In these scenarios, SS was used for all females in the purebred nucleus, with unlimited attempts to become pregnant with SS. As we still wanted to limit the number of surplus heifers, the proportion of purebred females used for crossbreeding was presimulated to $50 \%$ of the first-parity cows and $100 \%$ of the older cows in the $\mathrm{SH}$ nucleus, and $65 \%$ of the first-parity cows and $100 \%$ of the older cows in the SR nucleus.

\section{RESULTS}

\section{Economic Returns in SH Scenarios}

In the absence of GT, the operational returns decreased by $€ 4-9$ relative to the base scenario when SS was applied in the breeding scheme with purebred $\mathrm{SH}$ (Figure 3). The genetic returns did, however, increase by $€ 4$ to 16 when SS was applied. In the 50:0 SS scheme, the positive genetic return did not compensate for the negative operational return, and the total return was $€ 2$ /cow-year lower than the base scenario. The positive genetic return for the remaining SS schemes did compensate for the negative operational return; the total returns were between $€ 2$ (50:25) and $€ 10$ (90:45) higher per cow-year than the base scenario.

The cost of genotyping had adverse effects ( $€ 9$ to $-€ 10)$ on the operational returns in the PB scenarios with SS, evident from comparing the "GT" with "no 


\section{$€ /$ cow-year}

$-20-15-10-50 \quad 5101520253035404550556065707580859095100$

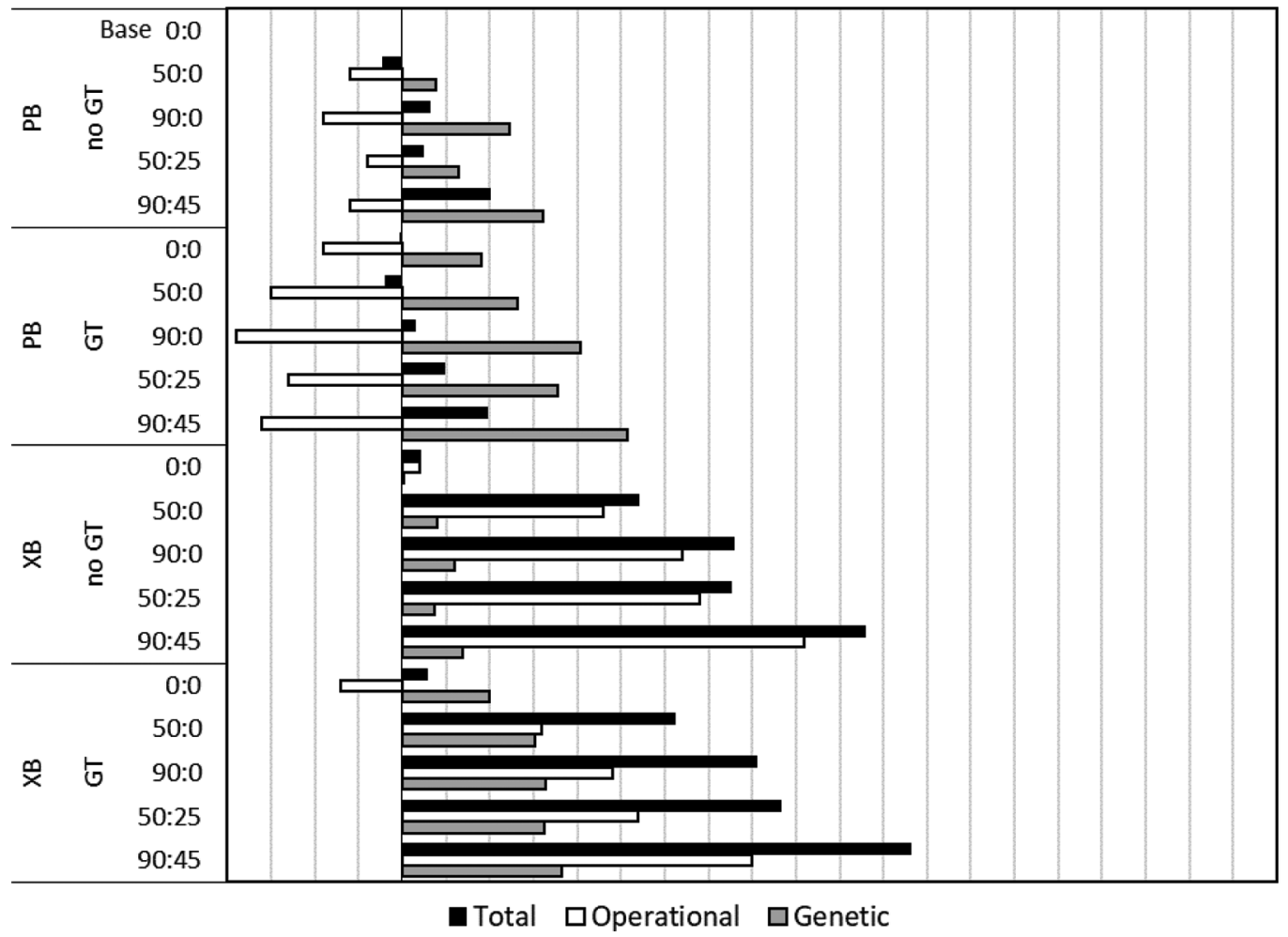

Figure 3. Operational (white), genetic (gray), and total economic returns (black) in $€$ /cow-year for simulated Swedish Holstein scenarios with pure-breeding $(\mathrm{PB})$ or crossbreeding $(\mathrm{XB})$, using genomic selection $(\mathrm{GT}$ ) or not using genomic selection (no GT) within sexed semen schemes where $0 \%(0: 0), 50 \%$ of the heifers (50:0), $90 \%$ of the heifers (90:0), $50 \%$ of the heifers $+25 \%$ of the first-parity cows (50:25), and $90 \%$ of the heifers $+45 \%$ of the first-parity cows (90:45), were bred to sexed semen.

GT" scenarios within SS schemes. However, the positive effects $(+€ 8-11)$ of GT on the genetic returns balanced out the total returns, as in the scenarios without GT.

Comparing the $\mathrm{XB}$ scenario with $\mathrm{PB}$ scenarios within SS schemes, crossbreeding reduced the genetic returns, but genetic returns were equal to or up to €7 larger than the genetic return in the base scenario. The operational returns were higher in the XB scenarios due to breed effects of SR, heterosis, and changes in herd dynamics. Without SS, the effect of crossbreeding (XB scenario 0:0) on the operational return was marginal $(+€ 2)$ because there were only $5 \%$ crossbreds in the herd (Table 3). Excluding GT, the effects on total returns of crossbreeding combined with any other SS scheme were $€ 27$ to 53 higher than the base scenario.

The combination of crossbreeding, SS, and GT in the $\mathrm{XB}$ scenarios provided the highest total returns. The SH scenario with the highest total return $(+€ 58$ higher than the base scenario) was the one with the most use of SS (90:45), which also provided the highest proportion of crossbreds in the herd (33\%; Table 3$)$.

\section{Economic Returns in SR Scenarios}

Without GT, SS decreased the operational returns by $€ 5$ to 7 in the PB scenarios with SR, relative to the base scenario for SR (Figure 4). When 50\% SS was used in heifers (50:0), the genetic return was $€ 23$ higher than the base scenario, whereas there was no further effect of combining SS in heifers with SS in first-parity cows (50:25). Increasing the use of SS in 90:0 and 90:45 had higher genetic returns ( $+€ 24$ and $+€ 27$, respectively.).

As in the SH scenarios, the cost of GT negatively affected the operational returns, but for SR, the effect was between $-€ 6$ and $-€ 7$ (i.e., smaller than for $\mathrm{SH}$ due to fewer replacement heifers). Except for the PB scenario with SS scheme 90:45 (+€4), GT positively affected the genetic return between $+€ 8$ and $+€ 10$. In the 90:45 SS scheme with GT, the total return was just $€ 18$ higher than the base scenario (i.e., €3 lower than the corresponding scenario without GT). The total returns for the remaining PB scenarios, including GT, were between $€ 17$ and $€ 20$ higher than for the base 
scenario, and $€ 1$ to $€ 3$ higher than for the corresponding PB scenarios without GT.

Without GT, crossbreeding increased the operational return: between $+€ 67$ and $+€ 73$ relative to the base scenario. Even the XB scenario without SS (0:0), where the proportion of crossbreds was $34 \%$ (Table 3), had a larger operational return. Furthermore, the genetic return in this scenario was the same as in the base scenario. The genetic returns in the remaining XB scenarios (without GT) were similar for 50:0 and 50:25 ( $+€ 8$ relative to the base scenario), but there was a larger effect of crossbreeding comparing 90:0 (+€19) to 90:45 (+€14). The total returns summed between $+€ 69$ and $+€ 87$ relative to the base scenario, where SS schemes 90:0 and 90:45 had the highest total returns.

The effect of combining crossbreeding with SS and GT in the XB scenarios (with GT) showed similar tendencies as in the XB scenarios without GT. The operational returns were between $€ 61$ and $€ 69$ higher than the base scenario, despite the cost of GT. The genetic returns gained from GT and were between $€ 10$ and €30 higher than the base scenario. The 90:0 SS scheme had higher genetic returns $(+€ 30)$ than the 90:45 SS scheme $(+€ 24)$. The total return was highest in the 90:0 SS scheme $(+€ 94)$, but nearly the same in the 90:45 SS scheme $(+€ 93)$.

\section{Herd Dynamics}

The number of heifers born each year was approximately identical across SS schemes for the PB scenarios but differed between breeds (Table 5). The SH scenarios needed more replacement heifers; thus, 13 more heifers were born each year, compared with SR scenarios. Only 2 crossbred heifers were born each year in the XB scenario with SH without the use of SS (0:0), but the number increased with the increasing use of SS. For SR, there was a considerable reduction of purebred heifers born in the XB scenario without SS (19 in 0:0) than the corresponding PB scenario (30 in 0:0). The number

\section{$€ /$ cow-year}

-20-15-10 -5 $0 \quad 5101520253035404550556065707580859095100$

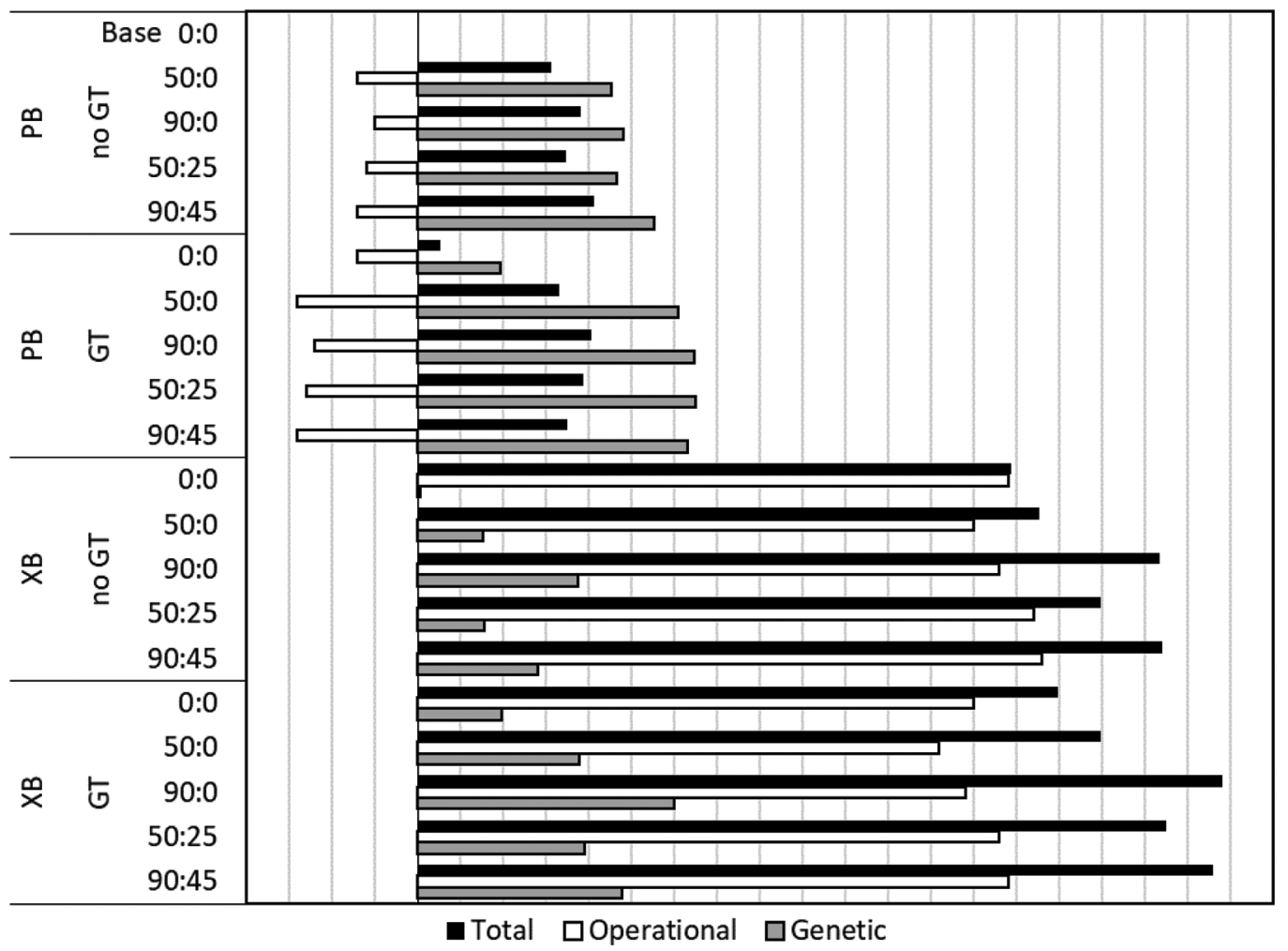

Figure 4. Operational (white), genetic (gray), and total economic returns (black) in €/cow-year for simulated Swedish Red scenarios with pure-breeding (PB) or crossbreeding (XB), using genomic selection (GT) or not using genomic selection (no GT) within sexed semen schemes where $0 \%(0: 0), 50 \%$ of the heifers (50:0), $90 \%$ of the heifers (90:0), $50 \%$ of the heifers $+25 \%$ of the first-parity cows (50:25), and $90 \%$ of the heifers $+45 \%$ of the first-parity cows $(90: 45)$, were bred to sexed semen. 
of crossbred heifers in the SR scenarios only slightly increased when SS was used.

In the PB scenarios and within the purebred nuclei in the XB scenarios, the age distribution for $\mathrm{SH}$ was $39 \%$ first parity, $24 \%$ second parity and $37 \%$ older cows within the herd. The age distribution for SR was $28 \%$ first parity, $20 \%$ second parity, and $52 \%$ older cows. By design, neither SS nor GT affected these distributions. However, there was a marginal effect of crossbreeding toward older cows. Therefore, fewer purebred first- and second-parity cows were available to select from in the SR scenarios compared with the SH scenarios.

\section{Sensitivity Analyses}

Applying different labor costs associated with replacement heifers had some effects when changing from the base (PB 0:0) to XB 90:45 in the SH herd scenarios. At no labor cost, the operational return was $1 \%$ higher in XB 90:45 relative to the base scenario, whereas it was $2.5 \%$ higher at the cost of $€ 261.6 /$ heifer per year. The reason behind this tendency was a considerable reduction $(\sim 12 \%)$ of young stock when crossbreeding was implemented, as shown in Table 5 . In the similar scenarios based on SR, the difference in operational return at no labor cost was $5.6 \%$, but as opposed to the $\mathrm{SH}$ scenario, the difference decreased to $4.0 \%$ at the highest simulated labor cost due to a small increase in young stock.

In the extreme scenarios simulating $100 \%$ use of SS in the XB scenarios, the proportion of crossbreds were $54 \%$ in the SH based scenario and $65 \%$ in the SR based scenario. Excluding GT, the operational returns were $+€ 290$ and $+€ 277$ for SH and SR, respectively, compared with the base scenarios within the respective breeds. Correspondingly, the genetic returns were $+€ 11$ and $+€ 12$; thus, the total returns were $+€ 301$ for $\mathrm{SH}$ and $+€ 289$ for SR. With the addition of GT, operational returns were $+€ 285$ for $\mathrm{SH}$ and $+€ 276$ for SR, whereas genetic returns were $+€ 20$ and $+€ 17$. Hence, the total returns were $+€ 305$ and $+€ 293$ for SH and $\mathrm{SR}$, respectively, compared with the base scenarios.

\section{DISCUSSION}

Overall, these simulations show positive total economic effects of using SS, GT, terminal crossbreeding, or a combination of them as breeding tools in a dairy herd. Terminal crossbreeding had negative effects on the herd's genetic return because crossbred animals were out of the oldest purebred dams in the herd. Nevertheless, there was a large and favorable effect of crossbreeding on the operational return, and thus the total return, due to complementation of breed effects, heterosis, and changes in herd dynamics. Disregarding the extreme scenarios simulated for the sensitivity analysis, the SH herd's best combination was using $90 \%$ SS in heifers and $45 \%$ SS in first-parity cows, combined with GT and crossbreeding. For the SR herd, the best combination was using $90 \%$ SS in heifers (and no SS in cows) and combined with GT and crossbreeding. However, due to differences in mainly reproduction traits between the 2 breeds, there were different effects of using the breeding tools. The simulated scenarios do not necessarily illustrate the best possible breeding schemes and should be interpreted as cases for the use of crossbreeding, SS, BS, and GS and combinations of these tools for 2 different breeds.

SimHerd Crossbred and ADAM did not allow for the best possible breeding scheme, and the economic returns were, therefore, likely a little underestimated. SimHerd Crossbred does not account for each animal's genetic level, and ADAM was used to study genetic progress. To match SimHerd Crossbred with ADAM, the age distribution obtained in SimHerd Crossbred was used as input parameters for ADAM. The fixed age distribution limited the ADAM model to select the genetically best cow dams within age groups and not across the entire herd. The consequence of this was evident in the PB scenarios with SR and the use of SS, where candidates to be covered with SS were limited to second-parity cows. Thus, potentially better cows from the third or later parities were ignored, and therefore the differences between these scenarios were somewhat limited. Another restriction in the SimHerd Crossbred model was a difference between the input parameters available for BS and crossbreeding; where 4 age groups (heifers, first parity, second parity, and older) were available for BS, just 3 were available for crossbreeding (heifers, first parity, and older). That means, when the SimHerd Crossbred output was used as input for the selection scheme in ADAM, there was an advantage of the selection scheme in the XB scenarios compared with the PB scenarios because in the PB scenarios, the model was "forced" to select among older cows than in the XB scenarios. Thus, the purebred females' genetic level was likely higher in the XB scenarios than in the $\mathrm{PB}$ scenarios due to selection differences.

In general, a high replacement rate is associated with a shorter generation interval, which is favorable for the genetic lag. Our results show that a lower replacement rate (reflected by the number of replacement heifers; Table 5) does not (necessarily) compromise the genetic lag between the simulated herd and the breeding population. Despite having a larger proportion of old cows in the herd, the generation intervals were lower in herds 
having SR than herds having SH. The SR scenarios needed fewer replacement heifers than SH scenarios, and therefore fewer cows were needed to be inseminated with dairy semen. Thus, the average age of the females producing replacement heifers was lower in the SR scenarios. In a recent review by De Vries (2020), he estimated the cow's economic optimum age at 5 lactations. In a study on the genetic effects of extended lactation, the use of SS and selection prioritized on the youngest females counteracted the negative effects on the genetic lag by having older cows in the herd (Clasen et al., 2019b). Thus, the optimal total economic return lies in the balance between having (older) cows in their most productive age and only selecting the genetically best animals as dams of future replacement heifers (De Vries, 2020).

\section{Sexed Semen and Genomic Selection}

Due to the small number of surplus heifers in the simulated scenarios, there was barely any selection among replacement heifers as future cow dams. Therefore, the economic potential of GT was neglected at this stage of selection. However, at the stage of selecting heifers for SS, the benefits of GT were utilized. Calus et al. (2015) concluded that GT was most beneficial when there was a large surplus of heifers, but the additional benefit of SS in the study was largest when the surplus was small. Nevertheless, the use of GT did show some benefits on the genetic return in the present study, despite a small number of surplus heifers. The reason is that the information of GT was used more than once throughout the breeding scheme: at selection of heifers for SS (except for SS scheme 0:0), selection of first-parity cows for SS (in SS schemes 50:25 and 90:45), and selection of cows for BS in second parity and later parities (PB scenarios) or selection of cows for crossbreeding in first and later parities (XB scenarios). The benefit of GT on the genetic return in $\mathrm{PB}$ scenarios without the use of SS (0:0) was due only to the selection of cows for BS. However, for the SR scenarios, there was no selection among second-parity and older cows in the 90:45 SS schemes (both PB and XB scenario), which may partly explain why the genetic return in these scenarios was lower than in 90:0. Hjortø et al. (2015) also found a larger benefit of GT when the information was used more than once - they too had only a small surplus of replacement heifers but included SS and BS in their simulation study.

Combining SS with GT had negative interaction effects on the genetic returns comparing SS schemes 90:0 and 90:45 in the SR scenarios. Furthermore, the genetic return was also lower comparing the 90:45 SS scheme with the extreme XB scenario, where SS was used as much as possible. On the other hand, the genetic returns increased throughout the corresponding scenarios for SH. Hjortø et al. (2015) found that herds with average reproductive performance ( $41 \%$ replacement rate) benefited more (genetically) from combining SS and GT than herds with good reproductive performance (38\% replacement rate). These findings comply somewhat with our findings, considering SR as having better reproductive performance than SH. From a genetics perspective, it would seem that maximizing the use of SS is not the most optimal breeding strategy at low replacement rates. However, the study from Hjortø et al. (2015) is based on a combination between SimHerd and ADAM as well, thus, this effect is likely due to limitations on the selection scheme when combining the 2 models, as explained earlier.

In the PB scenario with SH without SS (0:0), the cost of GT was only just covered by the genetic return in total return, whereas the similar scenario with SR had $+€ 4$ in total return at the same GT cost. The cost of GT was €22.5 in this simulation. A breakeven price for GT (without using SS) was calculated to €21 by Hjortø et al. (2015) when all heifers were genotyped in a herd with average reproductive performance and $€ 30.5$ in a herd with good reproductive performance.

\section{Sexed Semen and Beef Semen}

The difference in the genetic return between SS schemes 50:0 and 90:0 in the PB scenarios was larger in SH than in SR. The same trend was found in the study by Hjort $\varnothing$ et al. (2015) between breeding schemes using 40 and $80 \%$ SS in heifers, respectively, in herd scenarios having low versus high reproductive performance. In that study, the proportion of BS increased more between 40 and $80 \%$ SS in herd scenarios with low reproductive performance compared with high reproductive performance. Likewise, in the present study, the proportion of cows selected for BS increased more between 50:0 and 90:0 in SH compared with SR. Compared with the SR herd, the heifers in the SH herd had relatively better reproductive performance than the $\mathrm{SH}$ cows, which may explain why the herd benefited more from increasing SS on heifers.

The combination of SS and BS has potential economic as well as environmental benefits. Ettema et al. (2017) showed that reducing the number of surplus heifers using BS in combination with SS was economically beneficial if the cost of raising heifers was high compared with the market value. However, in cases where the price of crossbred beef $\mathrm{x}$ dairy calves was halved, or the market value of replacement heifers increased, 
it was more beneficial to produce a surplus of heifers. Therefore, the optimal strategy between producing beef $\mathrm{x}$ dairy cross calves versus surplus replacement heifers highly depends on the market situation, which may vary between countries and over time. Knapp et al. (2014) estimated that by reducing the replacement rate from 40 to $30 \%$, the contribution per replacement heifers to the whole-herd enteric methane emissions would be reduced by almost $20 \%$. Additionally, Holden and Butler (2018) estimated a $23 \%$ reduction in greenhouse gas emissions from beef production if $75 \%$ of the beef was produced from dairy farms (instead of $50 \%$ ), which can be achieved by using BS in dairy production.

In our simulations, BS was used in all scenarios. However, far from all dairy farms can raise beef $\mathrm{x}$ dairy crosses and dairy production. Farms without that capacity depend on sales contracts with beef producers. Furthermore, some beef producers may make demands on beef sire breeds used for crossbreeding, and also, some only accept bull calves.

The relative conception rate of SS versus CS was fixed at 0.85 in our simulations, which may have been a bit conservative. Studies from DFS countries suggests a relative conception rate closer to 0.90 (Borchersen and Peacock, 2009; Tyrisevä et al., 2017), while recent analyses on dairy farms from Italy (Bittante et al., 2020) and the United States (Maicas et al., 2020) suggest relative conception rates above 0.90 . In our simulations, $78 \%$ of the heifers inseminated with SS were expected to become pregnant after 2 attempts when the assumed conception rate for CS was 0.625 , and the relative rate for SS was 0.85 conception rate $=1-[1-(0.625 \times$ $\left.0.85)]^{2}=0.78\right\}$. If the relative conception rate had been simulated at levels of 0.90 or 0.95 , the proportion of pregnant heifers with SS after 2 attempts would be expected at 81 and $83 \%$, respectively. However, for the scenarios we simulated, the difference in heifers born from dams inseminated with SS would have been at most 2 additional heifers.

\section{Crossbreeding}

The proportion of crossbreds was much higher in the 0:0 scenario having SR than $\mathrm{SH}$ because of better reproductive performance and lower calf mortality, allowing for a smaller SR nucleus. However, there were larger increases in the crossbred proportions when SS was introduced in the SH herd than in the SR herd because the $\mathrm{SH}$ herd benefited more by increasing SS than the SR herd. Comparing the crossbred proportions in the 0:0 scenarios with the extreme scenarios using $100 \%$ SS shows a more considerable increase in crossbreds in the SH scenarios (5 vs. $54 \%$ crossbreds) than the SR scenarios (34 vs. $63 \%$ crossbreds).
In the XB scenarios based on SR, the crossbred proportion was $46 \%$ in 90:0 and 90:45, even though a slight increase was expected in the latter scenario. The explanation is that the scenarios had just a small difference in the proportion of first-parity cows selected for crossbreeding (10 and 15\%, respectively; Table 3). Furthermore, because of the low replacement rate in the SR scenarios (reflected by the heifers born; Table 5 ), the number of first-parity cows to select from was somewhat limited (17-18) and therefore, 10 or $15 \%$ would only make a difference of maximum one cow.

As expected, the genetic returns in the XB scenarios were lower compared with the PB scenarios within the same SS schemes because we selected among the oldest purebred cows in the nucleus for crossbreeding. Thus, the crossbred heifers born in the XB herd were at least one generation behind the purebred heifers born in the same herd. However, comparing the genetic returns between $\mathrm{PB}$ and $\mathrm{XB}$ scenarios should be done with caution because there were differences in the selection scheme due to limitations in the SimHerd Crossbred program described at the beginning of the discussion. Thus, if the selection was made the same way for both $\mathrm{PB}$ and $\mathrm{XB}$ scenarios, the genetic returns in the XB scenarios would have been expected to be even lower.

As reflected by the number of heifers born in the different scenarios (Table 5), the replacement rate was reduced when crossbreeding with SR was introduced in the $\mathrm{SH}$ herd, while it remained the same when crossbreeding with SH was introduced in the SR herd. As discussed previously, reducing the number of surplus replacement heifers has benefits in reducing the cost

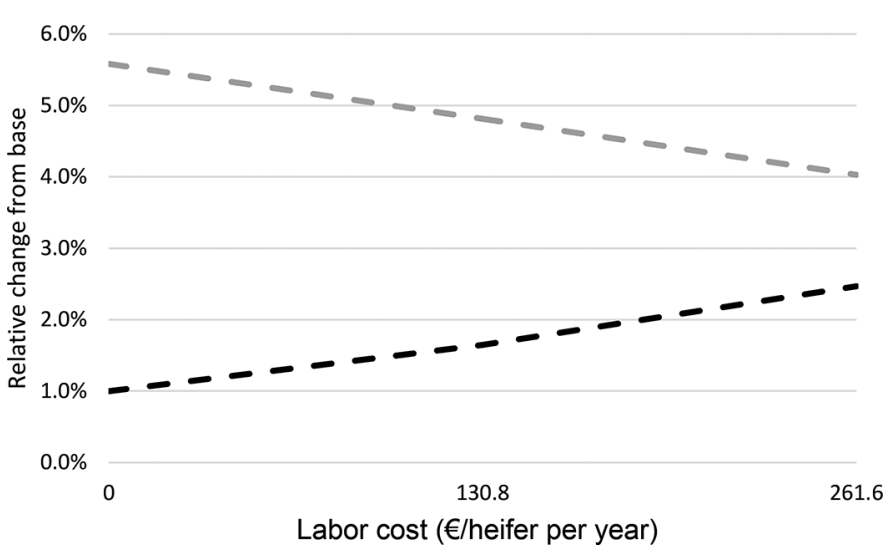

Figure 5. Relative change in operational return $(€ /$ cow-year $)$ at different yearly labor costs associated with young stock. Changes are relative to a pure-breeding herd without the use of sexed semen within the breed (Swedish Red or Swedish Holstein) and level of labor cost (€0, 130.8, or 261.6/heifer per year). Scenarios are Swedish Red terminal crossbreeding (dashed gray line), and Swedish Holstein terminal crossbreeding (dashed black line). Both scenarios are using $90 \%$ sexed semen in heifers and $45 \%$ sexed semen in first-parity cows. 
of rearing them - especially when this cost is high, as shown in Figure 5.

The breeds that are used for crossbreeding need to be economically equivalent for crossbreeding to be competitive to pure-breeding (Sørensen et al., 2008). The benefits of crossbreeding SR into an SH herd and vice versa were due to different effects. The $\mathrm{SH}$ breed is superior in milk production, whereas the SR breed has better functional traits, making the 2 breeds complement each other well. Thus, for the SH herd, crossbreeding with SR improved functional traits, and milk production was kept almost at the same level as the SH due to heterosis (Clasen et al., 2020a). For the SR herd, crossbreeding with $\mathrm{SH}$ improved the milk yield while keeping functional traits almost at the same level as purebred SR (Clasen et al., 2020b).

Our simulations using a terminal crossbreeding strategy cannot be used to determine the genetic effects of other crossbreeding strategies. For example, the crossbred animals were not used as breeding candidates, which is inevitable in rotational crossbreeding. Models for breeding value estimation in crossbreds were not available in ADAM, but are needed. Methods for routine genomic breeding evaluation in crossbred dairy cattle have been suggested (Esfandyari et al., 2015; VanRaden and Cooper, 2015), but until now, the number of genotyped crossbreds within the Swedish dairy cattle population has not been sufficient. This is somewhat a paradox because some (Swedish) farmers hesitate to introduce crossbreeding in their herds without using genomic breeding values (Wallin and Källström, 2019).

The extreme scenarios simulating maximum use of SS in a terminal crossbreeding system clearly showed the largest total economic benefits. The major benefits were increased operational returns, although genetic benefits were lower than the other XB scenarios for SR but slightly higher within the SH scenarios. Nevertheless, the total economic benefits of terminal crossbreeding were boosted in combination with SS and GT.

\section{Improvement of Reproduction}

This study's results indicate reproduction as a key trait for improving the genetic and total economic return from SS, GT, BS, and crossbreeding. It is well known that the Holstein breed's reproduction traits have eroded due to inbreeding (Bjelland et al., 2013) and decades of focus on high milk yield (Miglior et al., 2017). For the Nordic cattle breeds, reproduction traits have been included in the breeding goal since 1972 (Berglund, 2008), making it interesting to use SR for crossbreeding with Holstein from other countries. However, reproduction traits in $\mathrm{SH}$ are improving
(Växa Sverige, 2019). Thus, SR needs to improve in other traits to remain interesting for crossbreeding for farmers with SH herds.

\section{CONCLUSIONS}

Breeding tools including sexed semen, GT, BS, and terminal crossbreeding improved the total economic return individually and combined in simulated $\mathrm{SH}$ and SR herds. The results indicated that reproduction plays a key role in improving the benefit of any of the tools. The highest total economic returns were found in the scenarios where the breeding tools were used most, whereas the highest genetic returns depended on the breed's level of reproductive performance. Terminal crossbreeding resulted in a lower genetic return per generation born in the herd than the corresponding pure-breeding scenarios. However, the operational returns gained from terminal crossbreeding compensated for the higher genetic lag, which created higher total returns than pure-breeding. Terminal crossbreeding is but one crossbreeding strategy and does not include crossbred animals as breeding candidates. The genetic effects of other crossbreeding strategies remain to be investigated.

\section{ACKNOWLEDGMENTS}

This study was co-funded by GenTORE Horizon 2020 project (EU agreement No. 727213), Mistra Biotech under Stiftelsen för miljöstrategisk forskning (Mistra), "Increased profitability by using new breeding tools in dairy herds" (project no. V1330025) under Swedish Farmers' Foundation for Agricultural Research (SLF), Green Development and Demonstration Program (GUDP) under the Danish Directorate for Food, Fisheries and Agriculture, grant no. 34009-18-1365 (DairyCross project), and VikingGenetics. The authors have not stated any conflicts of interest.

\section{REFERENCES}

Bengtsson, C., H. Stålhammar, E. Strandberg, S. Eriksson, and W F. Fikse. 2020. Association of genomically enhanced and parent average breeding values with cow performance in Nordic dairy cattle. J. Dairy Sci. 103:6383-6391. https://doi.org/10.3168/jds 2019-17963.

Berglund, B. 2008. Genetic improvement of dairy cow reproductive performance. Reprod. Domest. Anim. 43:89-95. https://doi.org/ 10.1111/j.1439-0531.2008.01147.x.

Bérodier, M., M. Brochard, D. Boichard, C. Dezetter, N. Bareille, and V. Ducrocq. 2019. Use of sexed semen and female genotyping affects genetic and economic outcomes of Montbéliarde dairy herds depending on the farming system considered. J. Dairy Sci. 102:10073-10087. https://doi.org/10.3168/jds.2018-16041.

Bittante, G., R. Negrini, M. Bergamaschi, A. Cecchinato, and H. Toledo-Alvarado. 2020. Pure-breeding with sexed semen and cross- 
breeding with semen of double-muscled sires to improve beef production from dairy herds: Factors affecting heifer and cow fertility and the sex ratio. J. Dairy Sci. 103:5246-5257. https://doi.org/10 .3168/jds.2019-17932.

Bjelland, D. W., K. A. Weigel, N. Vukasinovic, and J. D. Nkrumah. 2013. Evaluation of inbreeding depression in Holstein cattle using whole-genome SNP markers and alternative measures of genomic inbreeding. J. Dairy Sci. 96:4697-4706. https://doi.org/10.3168/ jds.2012-6435.

Borchersen, S., and M. Peacock. 2009. Danish A.I. field data with sexed semen. Theriogenology 71:59-63. https://doi.org/10.1016/j .theriogenology.2008.09.026.

Buch, L. H., M. K. Sørensen, P. Berg, L. D. Pedersen, and A. C. Sørensen. 2012. Genomic selection strategies in dairy cattle: Strong positive interaction between use of genotypic information and intensive use of young bulls on genetic gain. J. Anim. Breed. Genet. 129:138-151. https://doi.org/10.1111/j.1439-0388.2011.00947.x.

Butler, S. T., I. A. Hutchinson, A. R. Cromie, and L. Shalloo. 2014. Applications and cost benefits of sexed semen in pasture-based dairy production systems. Animal 8:165-172. https://doi.org/10 .1017/S1751731114000664.

Calus, M. P. L., P. Bijma, and R. F. Veerkamp. 2015. Evaluation of genomic selection for replacement strategies using selection index theory. J. Dairy Sci. 98:6499-6509. https://doi.org/10.3168/jds .2014-9192.

Clasen, J. B., F. W. Fikse, M. Kargo, E. Strandberg, S. Østergaard, and L. Rydhmer. 2020b. Dairy cow crosses - Effects on herd dynamics and economic result. Report no. 152 from Department of Animal Breeding and Genetics, Swedish University of Agricultural Sciences. (In Swedish).

Clasen, J. B., W. F. Fikse, M. Kargo, L. Rydhmer, E. Strandberg, and S. Østergaard. 2020a. Economic consequences of dairy crossbreeding in conventional and organic herds in Sweden. J. Dairy Sci. 103:514-528. https://doi.org/10.3168/jds.2019-16958.

Clasen, J. B., A. Fogh, and M. Kargo. 2019a. Differences between performance of $\mathrm{F}_{1}$ crossbreds and Holsteins at different production levels. J. Dairy Sci. 102:436-441. https://doi.org/10.3168/jds .2018-14975.

Clasen, J. B., J. O. Lehmann, J. R. Thomasen, S. Østergaard, and M. Kargo. 2019b. Combining extended lactation with sexed semen in a dairy cattle herd: Effect on genetic and total economic return. Livest. Sci. 223:176-183. https://doi.org/10.1016/j.livsci.2019.03 .001 .

Dairy, N. Z. 2021. New Zealand Dairy Statistics 2019-20. Accessed Mar. 16, 2021. https://www.dairynz.co.nz/publications/dairy -industry/new-zealand-dairy-statistics-2019-20/.

De Vries, A. 2020. Symposium review: Why revisit dairy cattle productive lifespan? J. Dairy Sci. 103:3838-3845. https://doi.org/10 $.3168 /$ jds.2019-17361.

Dezetter, C., N. Bareille, D. Billon, C. Côrtes, C. Lechartier, and H. Seegers. 2017. Changes in animal performance and profitability of Holstein dairy operations after introduction of crossbreeding with Montbéliarde, Normande, and Scandinavian Red. J. Dairy Sci. 100:8239-8264. https://doi.org/10.3168/jds.2016-11436.

Esfandyari, H., A. C. Sørensen, and P. Bijma. 2015. Maximizing crossbred performance through purebred genomic selection. Genet. Sel. Evol. 47:16. https://doi.org/10.1186/s12711-015-0099-3.

Ettema, J. F., J. R. Thomasen, L. Hjortø, M. Kargo, S. Østergaard, and A. C. Sørensen. 2017. Economic opportunities for using sexed semen and semen of beef bulls in dairy herds. J. Dairy Sci. 100:4161-4171. https://doi.org/10.3168/jds.2016-11333.

García-Ruiz, A., J. B. Cole, P. M. VanRaden, G. R. Wiggans, F. J. Ruiz-López, and C. P. Van Tassell. 2016. Changes in genetic selection differentials and generation intervals in US Holstein dairy cattle as a result of genomic selection. Proc. Natl. Acad. Sci. USA 113:E3995-E4004. https://doi.org/10.1073/pnas.1519061113.

Hjortø, L., J. Ettema, M. Kargo, and A. Sørensen. 2015. Genomic testing interacts with reproductive surplus in reducing genetic lag and increasing economic net return. J. Dairy Sci. 98:646-658. https:// doi.org/10.3168/jds.2014-8401.
Holden, S. A., and S. T. Butler. 2018. Review: Applications and benefits of sexed semen in dairy and beef herds. Animal 12:s97-s103. https://doi.org/10.1017/S1751731118000721.

Jönsson, R. 2015. Estimation of heterosis and performance of crossbred Swedish dairy cows. MS Thesis. Department of Animal Breeding and Genetics, Swedish University of Agricultural Sciences.

Knapp, J. R., G. L. Laur, P. A. Vadas, W. P. Weiss, and J. M. Tricarico. 2014. Invited review: Enteric methane in dairy cattle production: Quantifying the opportunities and impact of reducing emissions. J. Dairy Sci. 97:3231-3261. https://doi.org/10.3168/jds .2013-7234.

Länsstyrelsen Västra Götaland. 2019. Bidragskalkyler för konventionell produktion

Maicas, C., S. A. Holden, E. Drake, A. R. Cromie, P. Lonergan, and S. T. Butler. 2020. Fertility of frozen sex-sorted sperm at $4 \times 106$ sperm per dose in lactating dairy cows in seasonal-calving pasturebased herds. J. Dairy Sci. 103:929-939. https://doi.org/10.3168/ jds.2019-17131.

McCullock, K., D. L. K. Hoag, J. Parsons, M. Lacy, G. E. Seidel Jr., and W. Wailes. 2013. Factors affecting economics of using sexed semen in dairy cattle. J. Dairy Sci. 96:6366-6377. https://doi.org/ $10.3168 /$ jds.2013-6672.

Miglior, F., A. Fleming, F. Malchiodi, L. F. Brito, P. Martin, and C. F. Baes. 2017. A 100-Year Review: Identification and genetic selection of economically important traits in dairy cattle. J. Dairy Sci. 100:10251-10271. https://doi.org/10.3168/jds.2017-12968.

Newton, J. E., B. J. Hayes, and J. E. Pryce. 2018. The cost-benefit of genomic testing of heifers and using sexed semen in pasture-based dairy herds. J. Dairy Sci. 101:6159-6173. https://doi.org/10.3168/ jds.2017-13476.

Nielsen, U.S., L.P. Sørensen, and G.P. Aamand. 2019. Status and plans genomic prediction. Nordic Cattle Genetic Evaluation (NAV) Workshop. Jan. 17, 2019. Nordic Cattle Genetic Evaluation. https: //www.nordicebv.info/wp-content/uploads/2019/01/Genomic -prediction-USN-NAV-workshop-jan-2019.pdf.

Norman, H. D., L. M. Walton, and J. W. Dürr. 2018. Reasons DHI cows exit the herd (2018). Accessed May 14, 2020. https://queries .uscdcb.com/publish/dhi/current/cullall.html.

Østergaard, S., M. G. G. Chagunda, N. C. Friggens, T. W. Bennedsgaard, and I. C. Klaas. 2005. A stochastic model simulating pathogen-specific mastitis control in a dairy herd. J. Dairy Sci. 88:42434257. https://doi.org/10.3168/jds.S0022-0302(05)73111-8.

Østergaard, S., J. F. Ettema, J. B. Clasen, and M. Kargo. 2018. SimHerd Crossbred for estimating the economic effects of systematic dairy crossbreeding. Proc. World Congr. Genet. Appl. to Livest. Prod. 927. World Congress on Genetics Applied to Livestock Production.

Pedersen, L. D., A. C. Sørensen, M. Henryon, S. Ansari-Mahyari, and P. Berg. 2009. ADAM: A computer program to simulate selective breeding schemes for animals. Livest. Sci. 121:343-344. https://doi .org/10.1016/j.livsci.2008.06.028.

SEGES.2011. Anvendelsen AfKønssorteretSædiDanmark. Accessed May 8, 2020. https://www.landbrugsinfo.dk/Kvaeg/Avl/Koenssorteret -saed/Sider/AnvendelseAfKoenssorteretSaedApril2011.aspx. （In Danish).

SEGES. 2020. Anvendelsen Af Kønssorteret Sæd i Danmark - Februar 2020. Accessed May 8, 2020. https://www .landbrugsinfo.dk/Kvaeg/Avl/Koenssorteret-saed/Sider/ AnvendelseAfKoenssorteretSaedFebruar2020.aspx.

Shonka-Martin, B. N., B. J. Heins, and L. B. Hansen. 2019. Threebreed rotational crossbreds of Montbéliarde, Viking Red, and Holstein compared with Holstein cows for feed efficiency, income over feed cost, and residual feed intake. J. Dairy Sci. 102:3661-3673. https://doi.org/10.3168/jds.2018-15682.

Sørensen, M. K., E. Norberg, J. Pedersen, and L. G. Christensen. 2008. Invited review: crossbreeding in dairy cattle: a Danish perspective. J. Dairy Sci. 91:4116-4128. https://doi.org/10.3168/jds .2008-1273.

Sørensen, M. K., J. Voergaard, L. D. Pedersen, P. Berg, and A. C. S $\varnothing-$ rensen. 2011. Genetic gain in dairy cattle populations is increased 
using sexed semen in commercial herds. J. Anim. Breed. Genet. 128:267-275. https://doi.org/10.1111/j.1439-0388.2011.00924.x.

Touchberry, R. W. 1992. Crossbreeding effects in dairy cattle: The Illinois Experiment, 1949 to 1969. J. Dairy Sci. 75:640-667. https:/ /doi.org/10.3168/jds.S0022-0302(92)77801-1.

Tyrisevä, A.-M., K. Muuttoranta, J. Pösö, U. S. Nielsen, J.-Å. Eriksson, G. P. Aamand, E. A. Mäntysaari, and M. H. Lidauer. 2017. Evaluation of conception rate in Nordic dairy cattle. Interbull Bull. 51:58-62.

VanRaden, P. M., and T. A. Cooper. 2015. Genomic evaluations and breed composition for crossbred U.S. dairy cattle. Interbull Bull. 49:19-23.

Växa Sverige. 2019. Hälsoläget-reproduktion. Accessed May 14. https://www.vxa.se/globalassets/dokument/statistik/bilaga -2018-2019-halsolaget-reproduktion.pdf. (In Swedish).

Växa Sverige. 2020. Växa Sverige DosShop. Accessed May 7, 2020. https://dosshop.vxa.se/index.html. (In Swedish).

Wallin, E., and H. N. Källström. 2019. Mjölkproducenters uppfattning om nya avelsverktyg. Urban and Rural reports 2019:2. Swedish
University of Agricultural Sciences, Department of Urban and Rural Development. (In Swedish).

Weigel, K. A. 2004. Exploring the role of sexed semen in dairy production systems. J. Dairy Sci. 87:E120-E130. https://doi.org/10 .3168/jds.S0022-0302(04)70067-3.

\section{ORCIDS}

J. B. Clasen (๑ https://orcid.org/0000-0001-7988-5400

M. Kargo () https://orcid.org/0000-0003-1981-2722

S. Østergaard (ㄱ https://orcid.org/0000-0002-8514-5414

W. F. Fikse 이 https://orcid.org/0000-0003-0578-0184

L. Rydhmer (1) https://orcid.org/0000-0002-2167-5475

E. Strandberg () https://orcid.org/0000-0001-5154-8146 